This is chapter 10 from "Digital Convergence - Libraries of the Future" Eds Rae Earnshaw and John Vince and reproduced here by permission of the publisher. It is copyright Springer Verlag 2008. Details of the book are at -

http: //Www. springer.com/uk/home/generic/search/results?SGWID=3-40109$22-173735439-\Theta$

\title{
10
}

\section{Libraries and Open Access: the Implications of Open- Access Publishing and Dissemination for Libraries in Higher Education Institutions}

Stephen Pinfield, University of Nottingham, UK

\subsection{Introduction}

This chapter discusses the consequences of open-access (OA) publishing and dissemination for libraries in higher education institutions (HEIs). To date, this topic has not received much coverage in the professional literature, despite the fact that a number of librarians have been leading advocates of OA. One explanation of this might be that librarians have been so focused on OA as a perceived answer to the 'serials crisis' that they have not looked beyond that at the long-term implications of OA for libraries. Another possible explanation is that librarians have habitually taken a wider view of information issues (wider that is than just that of the library as an organisation) and have therefore concentrated on the benefits of OA for the research community in general rather than on the consequences for libraries in particular. Whatever the explanation (there is probably some truth in both of the above for the library profession as a whole), it is certainly the case that a number of issues associated with the relationship between $\mathrm{OA}$ and libraries require further consideration. Key questions (which are addressed in this chapter) include:

- How might OA help information provision?

- What changes to library services will arise from OA developments (particularly if OA becomes widespread)?

- How do these changes fit in with wider changes affecting the future role of libraries?

- How can libraries and librarians help to address key practical issues associated with the implementation of OA (particularly transition issues)? 
By addressing these issues, it is hoped that this paper and other similar studies will give rise to more discussion of this strategically significant area for libraries.

This chapter will look at OA from the perspective of HE libraries and will make four key points:

1. Open access has the potential to bring benefits to the research community in particular and society in general by improving information provision.

2. If there is widespread open access to research content, there will be less need for library-based activity at the institution level, and more need for information management activity at the supra-institutional or national level.

3. Institutional libraries will, however, continue to have an important role to play in areas such as managing purchased or licensed content, curating institutional digital assets, and providing support in the use of content for teaching and research.

4. Libraries are well-placed to work with stakeholders within their institutions and beyond to help resolve current challenges associated with the implementation of OA policies and practices.

Each of these points will be discussed in turn, but first some remarks on the phenomenon of open access itself.

\section{2 'Open Access'}

'Open access' is normally defined as a situation where content is made available freely, immediately and without restriction. The content may then be used and re-used without restrictive copyright and permission barriers. A classic definition of open access is contained in the Budapest Open Access Initiative (2002) statement:

"The literature that should be freely accessible online is that which scholars give to the world without expectation of payment. Primarily, this category encompasses their peer-reviewed journal articles, but it also includes any unreviewed preprints that they might wish to put online for comment or to alert colleagues to important research findings. There are many degrees and kinds of wider and easier access to this litera- 
ture. By "open access" to this literature, we mean its free availability on the public internet, permitting any users to read, download, copy, distribute, print, search, or link to the full texts of these articles, crawl them for indexing, pass them as data to software, or use them for any other lawful purpose, without financial, legal, or technical barriers other than those inseparable from gaining access to the internet itself."

This definition covers what Peter Suber (2004) identifies as the two main components of OA: firstly, overcoming "price barriers" and secondly, overcoming "permission barriers". The removal of the price barriers allows the content to be freely accessed in full by all comers. The removal of permission barriers allows the material to be re-used "for all legitimate scholarly purposes".

In practical terms, OA is normally thought to be achievable via two routes: OA journals and OA repositories. OA journals are normally very much like traditional subscription journals in terms of content and presentation. They often contain peerreviewed, edited articles that are presented in periodical parts. However, they are usually funded in different ways, typically either by sponsorship or by publication charges. A publication charge is normally paid before publication by the author (or more accurately via the author by their institution or funder), and the article is then made available on OA. One recent variant of this business model (the so-called 'hybrid' model) allows authors to pay an OA fee to a publisher who will then make a particular paper in a subscription journal available on OA.

OA repositories on the other hand do not require a new business model, although some have suggested that as more content is made available in them new ways of paying for the production of the content will emerge. Repositories can be set up by subject communities, institutions, or other stakeholders, to collect material which (in the case of research outputs) is usually formally published elsewhere. A repository will contain electronic copies of journal articles (so-called 'eprints'), either in a form before they have been refereed ('preprints') or after ('postprints'). Repositories can also house other content including data, conference proceedings, and learning objects. Repositories are usually set up using international standards which mean they can interoperate; effectively creating a global network of interlinked repositories. 


\subsection{Benefits of OA}

The benefits of OA have been described in detail elsewhere (for example, Jacobs, 2006). Comments will be confined here to some key points closely associated with library work: dissemination, impact, use, and economics.

Firstly, dissemination. A key point here is that OA deepens "narrowcasting" and widens "broadcasting". It is often observed that the primary aim of researchers when they publish their results is "narrowcasting": to communicate their findings to a small specialised group of fellow researchers working in the same subject area (see Rowlands, Nicholas and Huntingdon, 2004, 1). These researchers are in a position to read, build on, and cite publications within the field. Bearing in mind the narrowcasting imperative, some have questioned whether OA is necessary. The implication is that research output only has to reach a narrow audience and that it usually does so. However, as librarians know, it is not the case that researchers have access to all of the literature in their field they require. Perhaps the most common request from researchers to their institutional library is for more journal subscriptions. The fact that publishers are continually marketing old and new journals to academics and librarians demonstrates that publishers themselves do not believe that researchers have access to all the content they need. Even narrowcasting then is not working in the current system. OA has the potential to improve the penetration of narrowcasting.

It will also widen broadcasting. OA will widen the dissemination of research output both within and outside the research community. Within the research community, OA material is more likely to reach scholars across different disciplinary boundaries (where the library may not previously have been able to justify a subscription). Outside the research community, OA content is more likely to reach audiences in the health and social care sector (to inform clinical practice), and the commercial sector (to improve knowledge transfer) and beyond. These two specific examples (healthcare and private industry) are ones of where widening the audience of research publications could bring significant benefits.

This leads to a second key issue to be discussed here: impact. Researchers write for impact. Impact is normally measured in terms of citations. Studies demonstrate that across various disciplines work made available on OA is cited more than work made available through other means (see Lawrence, 2001; Antelman, 2004; Harnad and Brody, 2004). Such empirical evidence can be used to demonstrate to researchers that 
it is in their interests to disseminate their work via OA routes. Since their status and esteem within their subject community relate closely to the impact they make, it is important for academics to maximise the impact made by their work.

However, the idea of 'impact' should perhaps also be seen in wider terms. From a public policy point of view, governments fund research in order to make an impact (in the broadest sense of the term) on the economy and society. One key element of this is knowledge transfer from research institutions to industry. Making the research literature available more easily to the commercial sector has enormous potential to improve knowledge transfer. Measuring this, however, is difficult - far more difficult than measuring citations. Nevertheless this should not stop people trying to get at evidence in this area. Houghton, Steele and Sheehan (2006) have provided some impressive early data demonstrating the economic value of increasing access to research outputs.

Evidence of this sort may help to counter the idea of the so-called 'free-rider problem'. This is the idea that making research output available on OA leads to a loss of income for publishers (and therefore the economy as a whole) from commercial consumers of the information, such as pharmaceutical or biotechnology companies. Such a loss would indeed represent a shift in the way publishing was funded as a consequence of OA. However, when it is understood that one of the key reasons the government sponsors research in the first place is to enable knowledge transfer and to promote innovation, then the 'free-rider problem' comes to look increasingly like the 'knowledge-transfer success'. This potential success remains to be analysed and quantified. More work is required in this area.

The third key benefit of OA moves beyond issues of dissemination (narrow or broad casting) and impact (narrowly or broadly defined) to the issue of use. Open access is not just about access but also about use. Gaining access is a necessary prerequisite to doing useful things with the content. For example, OA facilitates more effective search and retrieval of content, using technologies associated with the Open Archives Initiative (OAI). It also facilitates more sophisticated processing and analysis of content. This may often involve non-human processing, what Clifford Lynch (2006) has called "open computation". The content may be analysed or mined in various ways described by Lynch so that existing research may be accelerated and new avenues for research created. Access barriers associated with the traditional publish- 
ing system make such activities difficult if not impossible. Once again, more work is needed in this area but the potential benefits of these activities are clear.

A final point on the benefits of OA relates to the potential it has to correct a dysfunctional market. The recent independent studies of the journal publishing market have concluded that it is not working optimally because of structural problems. This was the conclusion of the UK House of Commons Science and Technology Committee in 2004 (House of Commons, 2004), and the European Commission sponsored study in 2006 (European Commission, 2006). The problems are based on the nature of the product itself - the journal. The fact that journals are collections of unique content means that each journal title is its own 'mini monopoly': the content cannot be easily substituted with an alternative title (Houghton, 2005, 170-171). Once a journal has established itself in its subject area, it increasingly becomes a 'must have' title, making demand for it relatively price inelastic. In other words, if the price is raised, people will still buy it. The fact that the consumers of the content (researchers) are not normally the purchasers helps to exacerbate the problem, since price signals do not operate as they would in most markets. Journal publishers have been able regularly to impose price rises way above inflation because of these features of the market, creating a situation where prices paid by customers are considerably above costs of production.

With potentially high profit margins available, the market has concentrated to become dominated by five or six major commercial companies. Furthermore, it is clear that the journal market is very unusual in that suppliers of established products can in fact increase their market share by raising their prices. In most markets a supplier increases market share by lowering the price, by improving the product or by increasing their marketing. However, in the academic journals market publishers can increase their market share by raising their prices because of the situation of their primary customers (libraries). Libraries work with relatively fixed budgets, increases over retail price inflation are unusual. If the journal publisher raises the price of a 'must have' journal, librarians have to cancel other titles in order to continue to a subscription to the 'must have' title. The publisher thereby increases market share.

These features of the market are magnified by the 'Big Deal' - electronic packages of journal titles. Most Big Deals are purchased as a whole with little flexibility to select or cancel individual titles. The attraction of the Big Deal for subscribers is that it gives them immediate access to more content. Publishers are able to provide more 
content in a context where marginal costs (costs over and above the fixed costs associated with producing the first copy of the content) are very low. In fact it is in their interests to offer as much content in their package as possible to make it more attractive to buy and less easy to cancel. In this way it is very easy for some of the large Big Deals to become 'must have' packages and for subscribers to find themselves locked in. If the package price goes up by more than inflation, librarians are now beginning to find themselves in a position where they may have to cancel other packages or groups of titles to afford them. Such trends only serve to increase concentration in the market further.

OA has the potential to address some of these systemic problems in the journals market by creating more competition. This would have a major impact on libraries which have in recent years had to devote considerable resources to managing the complexities associated with journal pricing models, licensing terms and delivery mechanisms.

Benefits in the areas of dissemination, impact, use and economics have meant that library managers have tended to support OA, at least in principle. Of course, the level of enthusiasm varies but librarians have often been amongst leading advocates of OA within their institutions and beyond.

\subsection{The Range of OA Material}

Most of the debate about OA in the academic community has until now concentrated on a particular type (albeit a very important type) of content: journal articles. That is clear from the Budapest Open Access Initiative definition of OA above. However, in order to think about the consequences of OA for library services, it is important to include the whole range of OA material that is currently emerging. There are at least five major categories of such material:

1. Current research output: typically in the form of journal articles, book chapters and other similar quality-controlled material.

2. Grey literature: ranging from conference proceedings to reports.

3. Data: some of which may have previously been published or purchased by libraries, such as census data and other publications by government or 
non-governmental organisations. Other data sets may previously have been publicly unavailable but can now be disseminated on the internet, such as large experimental data sets, some of which may be compiled collaboratively.

4. Out-of-copyright monographs: many of which are currently being retrospectively digitised as part of mass digitisation projects run by organisations such as Google and Microsoft.

5. Institutional digital assets: including materials such as electronic theses, and learning objects.

Many of the materials in the above categories represent high-quality information resources which have traditionally been purchased or licensed and then managed by libraries. Libraries have also traditionally managed other information materials such as metadata resources, including bibliographic databases. It is becoming increasingly common for some of these to become available on OA as well.

The question is what would be the implications for libraries if much of this material becomes available on $\mathrm{OA}$ ?

\subsection{The Impact of OA on Libraries}

Perhaps a useful way of considering the impact of OA on libraries is first to consider the role that libraries currently perform in making content available. First, in the paper-based environment, libraries in institutions carry out following processes:

- Selection of materials (title-by-title, normally including assessment of quality/authenticity, and liaison with academic staff)

- Procurement of materials (usually involving payment, budget management, etc)

- Cataloguing and classification to enable retrieval (metadata being made available to users via a public catalogue)

- Provision of additional indexes for article-level access (often themselves selected and purchased) 
Libraries and Open Access

- Physical preparation of materials (checking, labelling, tagging, binding etc)

- Access arrangements (including shelving of the physical item, organisation of physical space and guiding users around it)

- Circulation arrangements (including lending policies, self-service facilities etc)

- Ongoing collection management (may include relegation to stack/store)

- Support and training of users (enquiries, guides, training etc)

For paper-based content, these functions have to be performed at an institutional level since each institution is assembling its own physical collection. Individual libraries may achieve efficiencies in parts of the workflows by, for example, buying in externally-produced catalogue records, or outsourcing the procurement or physical preparation materials. Whether carried out in-house or externally, it is the library that is responsible for providing this service for its institutional users. It is assembling a local collection of resources for them the precise nature of which will be unique to that institution.

Many of the processes carried out in a print environment have an equivalent in an electronic one where the information materials are purchased or licensed. The physical preparation and management of materials are no longer necessary, nor is the provision of circulation services. However, content still has to be selected and acquired. Often there are new processes involved, such as product trials, and new complexities, such as dealing with package pricing models. Metadata describing the resources still has to be produced or purchased and then managed. The library catalogue remains important (usually providing access to electronic as well as hardcopy resources) alongside a number of other online indexes. Access arrangements for the electronic content need to be put in place, with the library setting up organised digital spaces to mirror the physical spaces they already provide. These online portals often simplify the experience for the user by providing a single sign-on authentication process or meta-searching across various resources. All of this needs to be underpinned by user support and training. In addition, there is at least one new process involved in electronic acquisition which does not apply to print media. This is the selection of different user interface and access arrangements. In some cases the same content can be 
available via different routes and with different user interfaces, and these need to be assessed and selected.

As far infrastructure is concerned, the library in an online environment is now relying on institutional IT services to support its work in delivering electronic resources (as well, of course, on the services of external providers). In some institutions, library services are in fact now delivered by the same organisation as IT services because of the considerable overlap in their roles.

What both these sets of processes (managing purchased print resources and managing purchased or licensed electronic resources) have in common is that they are selecting, aggregating and making available resources which are then available in a unique combination to a particular group of users. In any institution the combination of resources available to its own users will be different from those in other institutions. They will also often be accessed differently and may involve a different user experience.

Which of these processes then will need to be carried out by institutional libraries for OA material? In simple terms, very few (see Table 1). Particularly if OA was to become widespread, many of the functions carried out institution-by-institution in the current environment would no longer need to be duplicated in every institution for OA content. Neither the content itself nor the interface through which it is delivered would need to be selected. There would no longer be a need to acquire the content or to catalogue or classify it for a single set of institutional users. Many collection management functions would no longer be required. Local support and training would still be required but many services associated with pointing users to content would be better carried out at a higher (supra-institutional or national) level. Institutions would certainly be able to find efficiencies in these areas by eliminating unnecessary duplication if $\mathrm{OA}$ were to become widespread.

Of course, where there is a mixed economy of purchased, licensed and OA content it will be necessary for libraries in institutions to continue to guide their own users to all of this material via gateways such as library catalogues or institutional portal (indicated by '?' in Table 1). However, if OA were to become more widespread carrying out such work at an institutional level will become less necessary. Users would certainly begin to prefer global search services to locate information, as is increasingly the case even now. Libraries will more than ever need to ensure that data from their 
catalogues and other local search services are surfaced in the global search engines in order to ensure local content remains visible.

\begin{tabular}{|c|c|c|c|}
\hline & $\begin{array}{l}\text { Printed mate } \\
\quad \text { rial }\end{array}$ & $\begin{array}{c}\text { Electronic } \\
\text { content (pur- } \\
\text { chased) }\end{array}$ & OA materia \\
\hline Selection of content & $\checkmark$ & $\checkmark$ & $x$ \\
\hline Interface/access selection & $x$ & $\checkmark$ & $x$ \\
\hline Procurement & $\checkmark$ & $\checkmark$ & $x$ \\
\hline Cataloguing and classification /metadata & $\checkmark$ & $\checkmark$ & $?$ \\
\hline Provision of indexes & $\checkmark$ & $\checkmark$ & $x$ \\
\hline Physical preparation & $\checkmark$ & $x$ & $x$ \\
\hline Access arrangements & $\checkmark$ & $\checkmark$ & $x$ \\
\hline Circulation services & $\checkmark$ & $x$ & $x$ \\
\hline Collection management & $\checkmark$ & $x$ & $x$ \\
\hline User support and training & $\checkmark$ & $\checkmark$ & $\checkmark$ \\
\hline
\end{tabular}

Table 1: Libraries and content services in HEIs

\subsection{New Roles}

In an environment where OA were to become widespread new roles for information professionals would, however, be created. A significant number of these would be at what Lorcan Dempsey (2006) has called the "network level" OA is one of a number of trends that seems to be pushing a good deal of significant activity to this level. Subject communities, consortia of institutions, funders, or national agencies could usefully 
deliver a range of services to enhance access to content. New repositories might develop at the network level, PubMed Central and UK PubMed Central are early examples of such services. However, it would be particularly useful if other services could develop at this level provided by (within the language of OAI) 'Service Providers' as opposed to 'Data Providers'. Service Providers can provide access to a range of resources by harvesting metadata and/or content from repositories and other Data Providers and then delivering (at least some of) the following:

- metadata normalisation and enhancement

- automatic indexing and classification

- $\quad$ structured searching

- $\quad$ subject-specific gateways

- format-specific gateways (for example for theses)

- text/data mining and analysis of content

- $\quad$ citation analysis

- qualitative assessment of content

- $\quad$ proactive direction to content ('if you are interested in that, you may be interested in this')

Such services would complement those of standard web search engines by providing more sophisticated search and processing functionality.

All of these types of services are in fact required now. There are still too few Service Providers, for example, delivering even simple structured search services of OAIcompliant repositories. These will no doubt develop as more content becomes available on OA. Whilst these services will be created by teams including librarians, it is unlikely that they will normally be provided by institutional libraries. Such libraries do not usually have the capacity to develop services like these, nor is there any real reason for them to do so for a single institution. Providing such services at a higher level to serve a larger number of users would be more cost-effective. A search service for a particular subject community across different institutions is an obvious potential example of a useful service. 
However, librarians based in institutions are likely to have the opportunity to take on new roles. One of the key roles in an OA context is to set up and deliver repositories and the collection of services associated with them. Repositories might include the range of information materials produced in the institution, including research papers, data, reports, theses and learning objects. Consideration needs to be given at an institutional level to a range of technical, process and policy issues in setting up repositories serving local users (see Jones, Andrew and MacColl, 2005).

Libraries are ideally placed to take responsibility for delivering repositories in their institutions. As the role of librarians as the gatekeepers of externally-published information resources begins to shrink, their role as the guardians of internally-produced information resources has the potential to expand. Librarians are used to providing robust institution-wide services to a range of users. They have experience of working with people from different subject areas in order to support their activities and to deliver services to them. Librarians have a culture of customer service. They also have professional skills associated with the management and curation of information. Institutional repositories represent an opportunity to extend these skills into a new area on behalf of the institution.

However, repositories not only represent an opportunity but also a challenge to the library profession. As well as seeing repositories as opportunities for exercising information management skills and vehicles for achieving content dissemination, it is essential that repository managers set up services that further the strategic objectives of their institution. Repositories can be used to generate management intelligence for the institution and help to inform the development of research strategy. They can also be a vehicle for knowledge transfer and commercial liaison. The information profession has to ensure that its members are equipped to engage in the wide-ranging discussion associated with the general processes of the creation of research and teaching outputs as well as in the specific area of information management.

One of the specific functions of information management that will continue to be important is preservation. Libraries have traditionally had this role in a print environment and it is likely to continue in an electronic one. OA materials will need to be built into emerging strategies for digital preservation. Apart from the technical challenges, no clear organisational workflow or funding models for digital preservation have yet emerged. It is unclear whether or how institutions, national libraries, commercial organisations, or other agencies will be involved in digital preservation activ- 
ity. However, it is probable that all of these stakeholders will have some involvement. Some initial work has been done in this area, but a great deal remains to be done. In particular, the whole question of digital preservation needs to move from a largely theoretical or proof-of-concept stage to a practical production level stage. New roles will probably develop for institutional libraries as it does so.

Institutional libraries also have the potential to develop new or enhanced services to local users in supporting the use of content in research and teaching. Services might include sourcing, manipulating or digitising content on-demand for users. Particular areas of expertise, such as knowledge of intellectual property rights, will be essential here. Advising users on IPR in relation to their own content or that of others is required. This is especially important in complex areas where content can be easily made up of different components from different rights holders were different permissions are applicable; something which is becoming increasingly common.

Another practical on-demand service which might be developed at an institutional level is print-on-demand. If an increasing number of monographs are available online, dealing with the issue of how they can be read will become a priority. If the reader wishes to work on a text extensively, current screen technology may not make this comfortable or convenient. Of course, the technology may change in the five to ten years it will take for OA monographs to become very important. However, the problem is already real for purchased electronic books. In fact, the expansion of the e-book market has undoubtedly be a held up by this technological limitation, as well as the lack of a clear business model for the sale of in-copyright books in digital format. Librarians could help to address this for local users by providing services to print out e-books where copyright allows (which would be the case for OA books).

It is possible that the delivery of such a service could prompt a rethinking of the whole approach to storage of out-of-copyright monographs. Rather than multiple libraries storing duplicate copies of the same book, 'just in case' (with all the costs that involves), it may be more cost-effective for libraries to digitise the item and store it in digital form and then agree to provide a print-out when required, 'just in time'. There would then be no need to store the physical item. A costed life-cycle analysis would need to be carried out comparing storage, preservation, and delivery of physical items against electronic ones in order to inform decisions. The prejudice that librarians often have that digital preservation is very expensive needs to be balanced against 
the fact that physical preservation (when costed out properly) is also expensive (see Rusbridge, 2006).

Another practical service that it has been suggested could be provided by libraries in on OA world is administering payment of publication or OA charges. Libraries have teams of staff who currently administer periodical acquisitions and might redeploy them in this way. In some institutions libraries have already taken on this role in a small-scale way. The Wellcome Trust have provided funds to a number of institutions to pay publication charges for its grant holders, and in some cases this money is being managed by the library. It is arguable that libraries would be in a good position to take on this role especially if the market developed such that funds were not paid on a per-article basis but as a series of larger-scale pre-payments, effectively being institutional accounts with the publishers. This is already possible with OA publishers such as BioMed Central. It is even conceivable that in a market such as this subscription agents would morph to become intermediaries in the process. However, assuming a role like this has its downside for libraries. Libraries might be put in the difficult position of having to ration the available funds, making decisions about who could and could not publish, and where they could publish. More work needs to be done on how such a situation could be managed within institutions.

\subsection{The Future of Libraries}

These changes to the role of the library as a result of OA will, of course, contribute to some wider changes that are occurring for libraries and librarians. A few brief comments on this bigger picture should perhaps be made here in order to locate OA developments within their wider context from a library point of view. Over the last decade libraries have had to radically reinvent themselves with the burgeoning of electronic information. If anything, this is likely to continue. In the next decade the prospect of electronic information replacing print, rather than just coexisting with it, is likely to become more and more likely. The role of the library will need to continue to change.

Jerry D. Campbell (2006) has identified seven key roles that he feels libraries will (or have the potential to) carry out in the future:

- Providing quality learning spaces 
- Creating metadata

- Offering virtual reference services

- Teaching information literacy

- Choosing resources and managing licences

- Collecting and digitising archival materials

- Maintaining digital repositories

It is a little surprising that Campbell does not identify preservation (hardcopy or digital) as a future role of the library, although "collecting and digitising archival materials" and "maintaining digital repositories" imply this. The last three roles he does mention take the traditional role of libraries as collectors of content into new areas. This role encompasses material which will continue to be purchased and licensed; material of this sort will certainly continue to be important for the foreseeable future. Apart from in-copyright monographs, a great deal of value-added quality content will continue to be available only to purchasers. Even if much of the research literature is $\mathrm{OA}$, a hybrid OA-subscription environment will undoubtedly continue to be the norm for the information landscape as a whole. In addition, libraries will continue to collect, preserve and make available rare or unique material. Such content will remain the raw material of research. Finally, the management of institutional content in digital repositories is likely to become important in ways already discussed.

Three of the remaining four roles (metadata creation, reference services and training) are all about facilitating and supporting access to content. This activity is likely to continue to be important, although the place of the institutional library in this work is likely to change, particularly in the area of metadata creation (as above). Characterising the support role as "reference services" and "training" is perhaps a little restrictive. Libraries have the potential to deliver more proactive services than this implies, services that will need to be provided in a physical as well as a virtual world.

The first role that Campbell mentions continues a long established practice of the library providing physical spaces. The ways in which the spaces are conceived is changing rapidly but the fundamental provision remains important. This and all of the roles discussed by Campbell are opportunities to be grasped by the library profession. They are not a birthright. The library profession must take existing skills into new 
Libraries and Open Access

areas and develop new skills if it is to forge out a meaningful place for itself in the future of information provision.

\subsection{Implementing OA in Institutions}

Libraries and librarians have a strong record in pursuing an institution-wide mission to deliver services for a broad range of customers. Over the last 15 years in particular, libraries have also developed the role of partnering other institutional stakeholders in key developments and of themselves leading innovation. They are therefore wellplaced to work with stakeholders in their institution on addressing some of the key practical and policy issues associated with the implementation of OA.

Achieving cultural change within institutions in relation to OA is a major challenge, but one which many librarians have already begun to address. The way in which this can be achieved has been discussed in detail elsewhere (for example Ashworth, Mackie and Nixon, 2004). What is clear is that it requires libraries to take on a leadership role. It involves liaison (formal and informal) at a variety of levels within the institution and can only work if librarians have a good understanding of the entire information chain (rather than just the library's role in it) and of institutional strategy (rather than just the library's part in it). It also requires a long-term commitment, since if anything has become clear in the last five years it is that achieving cultural change is perhaps the major challenge associated with OA (Pinfield, 2005).

Another practical role that librarians can play is in discussions on the introduction of institutional OA policies and procedures. This has become an urgent priority in the UK since the introduction of OA mandates by a number of research funders, some of the central research councils and the Wellcome Trust. Informing researchers of their obligations as grant holders and creating procedures to make it easy to comply are immediate challenges. Some of the arrangements suggested by research funders have the potential between them to create confusion amongst researchers who may be unsure of where to self-archive their publications, for instance. Librarians can work within their institutions to establish policies to make things as straightforward as possible for researchers. It may be possible, for example, to advise researchers to self archive all publications in their institutional repository and put in place mechanisms to 
ensure that relevant publications are subsequently routed (on behalf of the researcher) to any other repositories as required.

A further practical challenge currently being addressed by librarians in many institutions is the question of the management of publication or OA fees. Many librarians have taken on the role of administering special Wellcome Trust funds provided for OA fees, not because they necessarily see it as their long-term role but in order to ensure that the money is used for the purpose intended by the Wellcome. They have also worked within their institutions to ensure that other funds can be made available for non-Wellcome researchers. In the UK, the research councils have stated that publication fees can be paid from funds claimed as part of institutional 'full economic cost' charges. In practical terms, what this means is that funds should be made available within institutions for researchers to use for the purposes of paying publication charges, although they can also use money from their individual direct grants (if they have them). However, there are few if any institutions where such funds are available. Because of their awareness of the issues, librarians have been leading voices in institutions ensuring that appropriate funds are identified, advertised and managed.

Librarians have also worked with stakeholders within and outside their institutions on useful experiments in the area of scholarly communication. Such work looking at policy development, creation of workable business models, and analysis of data needs to be continued in liaison with publishers and funders. In particular, libraries need to work with the stakeholders in identifying credible transition scenarios which maintain the strengths of the existing scholarly communication system but which can also lead to greater access.

\subsection{Conclusion}

The extent to which OA will become widespread in disseminating research output remains to be seen. It is likely that it will become more important, and possible that it will become the norm (at least in some disciplines). Changes are likely to take a decade or more to work through but the landscape is changing even now. It is difficult to predict when 'tipping points' will be reached but there is a need for libraries to be flexible and agile organisations which can respond. Librarians need to consider seriously the strategic implications of OA for their profession and organisations. Their 
role is changing, just as the information environment is changing. $\mathrm{OA}$ is one factor amongst many that is helping to shape the future environment in which the information professional will operate. However, in both the short and long-term, libraries and librarians should not just let change happen around them. They need to grasp the opportunity themselves to play an important role in helping to determine what the future of publishing and information management will look like.

\section{Acknowledgements}

Thanks to Ruth Jenkins and Karen Stanton for useful comments on drafts of this paper. This chapter is based on a presentation given to the JISC Open Access Conference in Oxford in September 2006. Thanks to a number of delegates at the conference for their comments.

\section{References}

Antelman, K. (2004) Do Open-Access Articles Have a Greater Research Impact? College \& Research Libraries 65 (5), 372-382. E-print available at: http://eprints.rclis.org/archive/00002309/.

Ashworth, S., Mackie, M. and Nixon, W.J. (2004) The DAEDALUS Project, Developing Institutional Repositories at Glasgow University: the Story so Far, Library Review 53 (5), 259264. E-print available at: http://eprints.gla.ac.uk/408/.

Budapest Open Access Initiative (2002), http://www.soros.org/openaccess/read.shtml.

Campbell, J.D. (2006) Changing a Cultural Icon: the Academic Library As a Virtual Destination, Educause Review, (January/February), 16-30.

Dempsey, L. (2006) Libraries and the Long Tail: Some Thoughts about Libraries in a Network Age, D-Lib Magazine 12 (6), http://www.dlib.org/dlib/april06/dempsey/04dempsey.html.

European Commission (2006) Study on the Economic and Technical Evolution of the Scientific Publication Markets in Europe, European Commission, Directorate-General for Research, http://ec.europa.eu/research/science-society/pdf/scientific-publication-study_en.pdf. 
Harnad, S. and Brody, T. (2004) Comparing the Impact of Open Access (OA) vs. Non-OA Articles in the Same Journals, D-Lib Magazine 10 (6), http://www.dlib.org/dlib/june04/harnad/06harnad.html.

Houghton, J. (2005) Economics of Publishing and the Future of Scholarly Communication. In Gorman, G.E. and Rowland, F. (eds), Scholarly Publishing in an Electronic Era, International Yearbook of Library and Information Management, 2004-2005, Facet Publishing.

Houghton, J., Steele, C. and Sheehan, P. (2006) Research Communication Costs in Australia: Emerging Opportunities and Benefits. Department of Education, Science and Training (Australia), http://www.dest.gov.au/NR/rdonlyres/0ACB271F-EA7D-4FAF-B3F70381F441B175/13935/DEST_Research_Communications_Cost_Report_Sept2006.pdf.

House of Commons Science and Technology Committee (UK) (2004) scientific publications: Free For All? Tenth Report of Session 2003-04, HC 399, http://www.publications.parliament.uk/pa/cm200304/cmselect/cmsctech/399/399.pdf.

Jacobs, N. (ed) (2006) Open Access: Key Strategic, Technical and Economic Aspects. Chandos Publishing.

Jones, R., Andrew, T. and MacColl, J. (2006) The Institutional Repository. Chandos Publishing.

Lawrence, S. (2001) Free Online Availability Substantially Increases a Paper's Impact, Nature, 411 (31 May), 521, and Nature: webdebates, http://www.nature.com/nature/debates/eaccess/Articles/lawrence.html.

Lynch, C. (2006) Open Computation: Beyond Human Reader-Centric Views of Scholarly Literatures. In Jacobs, N. (ed) Open Access: Key Strategic, Technical and Economic Aspects. Chandos Publishing.

Pinfield, S. (2005) Self-Archiving Publications. In Gorman, G.E. and Rowland, F. (eds), Scholarly Publishing in an Electronic Era, International Yearbook of Library and Information Management, 2004-2005, Facet Publishing. E-print available at http://eprints.nottingham.ac.uk/archive/00000142/.

Rowlands, I., Nicholas, D. and Huntingdon, P. (2004) Scholarly Communication in the Digital Environment: What Do Authors Want? Findings of an International Survey of Author Opinion: Project Report. CIBER: Centre for Information Behaviour and the Evaluation of Research, Department of Information Science, City University, http://www.ucl.ac.uk/ciber/ciber-pa-report.pdf.

Rusbridge, C. (2006) Excuse Me...Some Digital Preservation Fallacies? Ariadne, (46), http://www.ariadne.ac.uk/issue46/rusbridge/. 
Libraries and Open Access

Suber, P. (2004) Praising Progress, Preserving Precision. SPARC Open Access Newsletter, (77), http://www.earlham.edu/ peters/fos/newsletter/09-02-04.htm. 